\title{
MITOCHONDRIA-TARGETED MESOPOROUS SILICA NANOPARTICLES NONCOVALENTLY MODIFIED WITH ALKYLTRIPHENYLPHOSPHONIUM CATION: ROLE OF LENGTH OF HYDROPHOBIC TAIL
}

\author{
A. Ibragimova', D. Gabdrakhmanov', L. Vasileva', A. Tyryshkina ${ }^{1,2}$, \\ A. Lyubina', A. Voloshina', A. Lamberov' ${ }^{2}$, C. Sibgatullina ${ }^{2,3}$, \\ D. Samigullin ${ }^{2,3}$, K. Petrov ${ }^{1}$ and L. Zakharova ${ }^{1}$ \\ ${ }^{1}$ Arbuzov Institute of Organic and Physical Chemistry, FRC Kazan Scientific Center, \\ Russian Academy of Sciences, 420088, Russia, Kazan, Arbuzov st., 8. \\ ${ }^{2}$ Kazan (Volga region) Federal University,420008, Russia, Kazan, Kremlyovskaya st., 18. \\ ${ }^{3}$ Kazan Institute of Biochemistry and Biophysics of the Kazan Scientific Center \\ of the Russian Academy of Sciences, 420111, Russia, Kazan, Lobachevsky str. 2/31.
}

DOI: 10.19163/MedChemRussia2021-2021-75

E-mail:alsu_i@iopc.ru

Targeted delivery of drugs has a special significance in the treatment of dangerous diseases, since it allows to reduce side effects, to increase bioavailability and to improve the effectiveness of the system. Recently, much attention has been paid to mitochondrion as a key target, which is due to their biochemical role in regulating the energy metabolism of cells. They also play significant role in the regulation of programmed death of the cell (apoptosis). Various compounds are used as vectors for mitochondria-targeted delivery of drugs including triphenylphosphonium (TPP) cation.

In this investigation, synthesis of mesoporous silica nanoparticles (MSN) noncovalently modified by alkyltriphenylphosphonuim bromides with various hydrophobicity (TPPB- $\mathrm{n}$, where $\mathrm{n}$ is the number of carbon atoms in $n$-alkyl tails; $n=7,9,16$ ) has been performed. The main goal of the study was the revealing of the influence of the length of the alkyl tail on the permeability of mitochondrial membrane for drugs. Efficiency of modification, structural and morphological characteristics of obtained nanosystems have been evaluated using spectrophotometry, adsorption and desorption of nitrogen, IR spectroscopy, X-ray diffraction and thermogravimetric analyses and scanning electron microscopy. It has been calculated, that specific surface area of pores of MSNs modified by TPPB-7, TPPB-9 and TPPB-16 equals $1426 \mathrm{~m}^{2} / \mathrm{g}, 1315 \mathrm{~m}^{2} / \mathrm{g}$ and $891 \mathrm{~m}^{2} / \mathrm{g}$, respectively. It has been revealed, that modified compositions exhibited insignificant cytotoxicity toward normal Chang liver cell lines and WI38 lung tissue cells in vitro. Fabricated nanosystems demonstrated the capability to penetrate into M-HeLa, A-549 and PANR tumour cells and selective toxicity toward cancer cells in TPPB-7 < TPPB-9 < TPPB-16 series.

This work was financially supported by Russian Science Foundation (project № 19-73-30012). 